\title{
Internalities and Paternalism: Applying the Compensation Criterion to Multiple Selves across Time
}

\author{
6 October 2008
}

Eric Rasmusen

\begin{abstract}
One reason to call an activity a vice and suppress it is that it reduces a person's future happiness more than it increases his present happiness. Gruber \& Koszegi (2001) show how a vice tax can increase a person's welfare in a model of multiple selves with hyperbolic preferences across time. The present paper shows that an interself analogy of the Kaldor-Hicks compensation criterion can justify a vice ban whether preferences are hyperbolic or exponential, but subject to the caveat that the person has a binding constraint on borrowing.
\end{abstract}

Dan R. and Catherine M. Dalton Professor, Department of Business Economics and Public Policy, Kelley School of Business, Indiana University. Erasmuse@indiana.edu. http://www.rasmusen.org. This paper: http://www.rasmusen. org/papers/internality-rasmusen.pdf.

Keywords: Internalities, sin tax, moral regulation, Kaldor-Hicks criterion, time inconsistency, hyperbolic preferences.

I thank Kevin Du and participants in seminars at Bath, Bern, East Anglia, and the 2008 Midwest Law and Economics Meeting for their comments, and Nuffield College, Oxford, for its hospitality. 


\section{Introduction}

A common justification for laws to discourage vice is that although the vice makes a person happy in the present, it will cause him even more unhappiness in the future. Gruber \& Koszegi (2001) formalize this argument in the context of smoking and show how cigarette taxes can raise welfare. They build a model of multiple selves linked across time by altruism and the addictive consequences of smoking. They call these consequences "internalities" between different time-selves of the same person in analogy to "externalities" between different people. Their model assumes hyperbolic discounting and as a welfare criterion they maximize the utility of the first of the multiple selves.

In this paper I will show that neither hyperbolic discounting nor that particular welfare criterion is necessary for the idea of discouraging vice to protect future selves to be valid. I will use a model of one person who is divided into three selves across time. A key assumption will be that the person cannot borrow against future income. Given that assumption, suppression of the vice combined with a transfer from a future self to a present self results in a Pareto improvement. If the transfer is not made, there is still a Kaldor-Hicks improvement.

What is most important in Gruber \& Koszegi (2001) is perhaps not the hyperbolic discounting but the idea of multiple selves and the inefficiency that can arise from internalities. If we are prepared to accept a multiple selves model and the idea of basing a welfare function on it, then paternalism can be desirable even if the person's discounting is orthodoxly exponential.

The Kaldor-Hicks argument has important caveats, however, because it depends on transfers that have their own internalities, those created by intraself altruism. The present self cares about the future self's consumption, so a transfer of future wealth to the present is not an unmixed blessing for him - he cares that his future self consumes less. Thus, we will have to inquire as to whether the present, vice- tempted, self is is willing to accept a compensating transfer that will increase present consumption at the expense of future consumption.

I will start by laying out the three-period model used throughout the paper, and then explore different variants of the model. First we will assume 
that utility is linear in consumption so as to lay out starkly the conditions under which the intraself Kaldor-Hicks criterion recommends regulation of smoking. We will use situations with constrained borrowing, unconstrained borrowing, and saving to show how the laissez faire transfers of consumption across time periods affect the Kaldor-Hicks transfers related to smoking. Then we will let utility be concave in consumption so that the person will wish to smooth consumption over time and show the effect of borrowing constraints in that context.

\section{The Model}

A person lives for three periods labelled 0,1 , and 2. He receives the same income, $W$, in each period. We will denote his consumption of the single good by $C_{0}, C_{1}$, and $C_{2}$. Our person can save at interest rate $r$, but he cannot borrow. We will denote wealth in each period as $W_{0}, W_{1}, W_{2}$, where $W_{0}=W$ and the later wealths depend on earlier saving.

In period 1 , the person chooses between smoking $(X=1)$ or not smoking $(X=0)$. We will assume the monetary cost of smoking is negligible, so it does not reduce consumption. ${ }^{1}$ If the person chooses to smoke he receives 1 unit of utility in period 1 and loses $\alpha$ in period 2, where we assume that $\alpha>1$ so the loss is bigger than the gain.

Total utility is given by the following function of the three consumption choices and the smoking choice:

$$
U_{0}=U\left(C_{0}\right)+\beta \delta\left(X+U\left(C_{1}\right)\right)+\beta \delta^{2}\left(-\alpha X+U\left(C_{2}\right)\right)
$$

with $0 \leq \beta<1$ and

$$
0 \leq \delta<\frac{1}{1+r}
$$

The "consume-early" assumption, inequality (2), says that the person's rate of time preference is greater than the interest rate.

We will assume for the first part of the paper that utility is linear in consumption $(U(C)=C)$. Later, relaxing this assumption and the assumption

\footnotetext{
${ }^{1}$ The reader dissatisfied with smoking having no effect on consumption may replace smoking with a different vice, e. g. self-drawn tattoos or unhealthy sexual practices.
} 
of equal incomes will introduce the complication of "bequests" motivated by consumption smoothing.

Utility function (1) includes both the case of conventional exponential discounting and the case of quasi-hyperbolic discounting in the style of Laibson (1997). Our person has an exponential discount factor of $0 \leq \delta<\frac{1}{1+r}$ (so his rate of time preference is greater than the market interest rate) and a hyperbolic adjustment parameter of $\beta$, where $0 \leq \beta<1$. If $\beta=0$ or $\delta=0$ he does not care at all about the welfare of his future self; if $\beta=1$ he has a standard exponential-discounting utility function. ${ }^{2}$

A value of $\beta$ between 0 and 1 leads to the standard features of hyperbolic discounting: besides preferring earlier consumption to later, the person puts a special value on consumption immediately instead of later. As a result, in period 0 his tradeoff between consumption in periods 1 and 2, both distant, is different from the tradeoff he would make in period 1, when period-1 consumption is immediate. This introduces a time inconsistency absent when $\beta=1$ and discounting is purely exponential.

We will view this person as consisting of three selves, Self 0 , Self 1 , and Self 2. Self 0's utility function, defined over the present and future decisions viewed from Period 0, is equation (1). Self 1 and Self 2 have the utility functions:

$$
U_{1}=X+U\left(C_{1}\right)+\beta \delta\left(-\alpha X+U\left(C_{2}\right)\right)
$$

and

$$
U_{2}=-\alpha X+U\left(C_{2}\right)
$$

The model sets up as simply as possible three periods when smoking has no immediate effect on utility (period 0), has a positive effect (period 1), and has a negative effect (period 2). As far as smoking goes, Self 0 is close to what some would call "the long-run consumer" who has preferences but does not choose the action, but Self 0 does choose his own consumption.

\footnotetext{
${ }^{2}$ Phelps \& Pollack (1968) had used the quasi-hyperbolic form to discount generations of people over time. Laibson (1997) applied it to within the self and named it "quasihyperbolic". True "hyperbolic" discounting, proposed by Chung \& Herrnstein (1961) in connection with a particular theory of behavior, has similar qualitative features but is more complicated to work with. See Angeletos, Laibson, Repetto, Tobacman \& Weinberg (2001) for an explanation of the differences.
} 
Self 0 cares about Self 1 only through actions that occur in Self 1's period, and about Self 2 only through actions that occur in Self 2's period. Self 0 does not care that Self 1 derives utility from Self 2's consumption. If he did, Self 2's consumption would count double in Self 0's utility function. That is plausible if Self 0's utility arises from thinking of how happy he will feel in the future instead of from thinking of how happy particular actions will be making him in the future. Caplin \& Leahy (2004) cite Loewenstein (1992) as saying this is the Jevons approach to utility. Here, we are instead using what he calls the Samuelson approach. I take the Samuelson approach as better reflecting the idea that each self is like a person deciding on his future actions, and because the Jevons approach makes most sense when memory as well as anticipation affect utility (as Caplin \& Leahy [2004] do assume).

Memory yields no utility in our utility function here. In period 1 the person derives no pleasure from remembering his consumption in period 0 . For our purpose of looking at the amoking decision, including memory would make little difference, so long as we assume that memory yields less utility than the event remembered, though it would add many extra terms to the equations. It would make smoking somewhat more attractive, since in Period 2 the person would derive utility from Period 1's pleasure from smoking.

\section{The Equilibrium Choices under Laissez Faire}

Self 0 controls the value of $C_{0}$, Self 1 controls $X$ and $C_{1}$, and Self 2 controls $C_{2}$. This distribution of power, not the equal incomes across time, is the true distribution of property rights.

Let us work back from the end. Self 2 would consume his entire wealth, so $C_{2}=W+(1+r)\left(W_{1}-C_{1}\right)$. If he could choose variables from earlier periods, he would choose $X=0, C_{0}=0$, and $C_{1}=0$ : a ban on smoking, and zero consumption in the earlier periods so he would have more consumption himself.

Self 1 would maximize (3) by choice of $X$ and $C_{1}$ subject to the constraint that $C_{2}=W+(1+r)\left(W_{1}-C_{1}\right)$. Under our assumption that utility is linear he would have a corner solution and consume his entire wealth: $C_{1}=W_{1}$. He derives utility from Self 2's consumption, but it is discounted by $\beta \delta$, which is less than $1 /(1+r)$ by the consume-early assumption. He would choose 
$X=1$ if $1-\beta \delta \alpha>0$, i.e. if

$$
\alpha<\frac{1}{\delta \beta}
$$

If he could control $C_{0}$ and $C_{2}$, Self 1 would choose $C_{0}=0$ to increase his own consumption, and he would choose $C_{2}=W_{2}$.

Self 0 , like Self 1 , is subject to the consume-early assumption and so will choose $C_{0}=W$.

If Self 0 could control $C_{1}$ he would set $C_{1}=W$, just as Self 1 would, because of the consume-early assumption. He would choose $X=1$ if $\beta \delta-$ $\beta \delta^{2} \alpha>0$, i.e. if $1-\delta \alpha>0$. so he would choosing smoking for period 1 if

$$
\alpha<\frac{1}{\delta}
$$

To sum up: in equilibrium consumption would be equal in all periods and Self 1 would smoke if $\alpha>\frac{1}{\delta \beta}$ but not if $\alpha<\frac{1}{\delta \beta}$.

\section{Welfare Analysis: The Precommitment Criterion}

Is the laissez faire outcome of smoking and no savings optimal? To answer, we need to define "optimal". An obvious welfare criterion is Pareto optimality applied across selves. Let us say that a pattern of choices is intraself pareto optimal if no change can be made which would make some self better off without making some other self worse off according to the particular selves' utility functions. This has frequently been applied to multiple selves models (e.g. in Bernheim \& Rangel (2007)), since it seems unobjectionable as a minimal condition for optimality.

We have seen, however, that the three selves have contradictory preferences for smoking and consumption. When Selves 0 and 2 do not want smoking but Self 1 does, what should the social planner do? The situation is intraself Pareto optimal, but it would also be intraself Pareto optimal if the regulator banned smoking. The criterion does not provide a reason to choose one policy over the other.

A second welfare criterion is what I will call the "precommitment criterion": maximize Self 0's utility by seeing what would happen if he could 
directly commit to a future course of action, rather than having to try to manipulate his future selves.

The Precommitment Criterion: A change in the value of the choice variables is an improvement if it increases the utility of Self 0.

The attraction of the precommitment criterion is that it is the same as our standard approach under exponential utility, simply adding the recognition that the social planner will have to somehow constrain the future selves so that they act in accord with Self 0's wishes. The precommitment criterion is commmonly used in the literature, almost always in connection with decisions about consumption and savings (see, e.g. Laibson (1997), Harris \& Laibson (2001), and Krusell \& Smith (2003)).

Gruber \& Koszegi (2001) use a model of a divided self to look at whether smoking should be taxed- a model focussing not on consumption, but on vice. In their model, a person lives for a finite number of periods and must decide the amount of smoking and other consumption for each period. Smoking is addictive, so smoking more now lowers future utility. Discounting is quasi-hyperbolic rather than exponential, so decisions are time inconsistent; in period 1 the person would deviate from the period 1 smoking level he thought was best in period 0 . They use the precommitment criterion, maximizing Self 0's utility, and show that a large tax on cigarettes is optimal. O'Donoghue \& Rabin (2003) also looks at sin taxes with time-inconsistent consumers to make the point that time-consistent consumers may be hurt very little and time-inconsistent consumers helped a great deal by sin taxes. Caplin \& Leahy (2004) and Whitman (2006) criticize this focussing on the welfare of the "long-run" or earliest self- the "dictatorship of the present". In effect, focussing on the early self asks what would happen if a person could commit himself to future actions (in this case, cigarette smoking), and how government action could bring consumption closer to that outcome when personal commitment is not possible.

Let us start then by following Gruber \& Koszegi (2001) and privileging the earliest self. The social planner's role is then to act to allow the person to commit to all his future actions and thereby avoid the consequences of time inconsistency. ${ }^{3}$

\footnotetext{
${ }^{3}$ There are two variants of the precommitment criterion. In one, it is literally the earliest
} 
Using the precommitment criterion, the laissez faire outcome fails to maximize welfare if $\alpha \in\left(\frac{1}{\delta}, \frac{1}{\beta \delta}\right)$ because Self 0's optimality condition (6) and Self 1's optimality condition (5) conflict. The optimality conditions differ whenever there is hyperbolic discounting and $\beta<1$.

Self 1 trades off the present period 1 against the future period 2 at the high rate of 1 to $\beta \delta$, whereas Self 0 trades off the future period 1 against the distant-future period 2 at the lower rate of $\delta$. The problem is not that sensations further in the future should not be treated as less important- a low $\delta$ by itself would not introduce a reason for paternalism- but quasi-hyperbolic discounting makes the present period count too heavily.

If discounting is exponential, i.e. if $\beta=1$, then there is no time inconsistency and the precommitment criterion will not call for a paternalistic ban on smoking. Self 1 will make the correct smoking decision even without coercion. It is still true that smoking hurts Self 2, possibly by much more than it helps Self 1, but if the exponential discount factor $\delta$ is small enough that Self 1 would choose smoking, then it is small enough that Self 0 cares much more about period 1 smoking utility than period 2 smoking disutility.

The precommitment criterion can also be applied to consumption rates, but it would suggest no change from laissez faire. The positive analysis above showed that Self 0 wants zero savings and $C_{0}=C_{1}=C_{2}=W$ anyway, which precommitment is unnecessary to attain. Borrowing would be a different matter, but that is ruled out for the moment by assumption.

Thus, using the precommitment criterion, a paternalistic ban on smoking might be desirable when discounting is hyperbolic to avoid the consequences of the high value placed on present satisfaction. Self 0, like Self 1, places high value on present satisfaction, but the smoking decision is in period 1, so Self 0 wishes to override Self 1's desires because of the harm they

self whose utility is maximized. In the other, the modeller creates a "long-run self" who exists before Self 0 and who derives no utility from present sensations, only from future sensations. The long-run self approach can be attractive in the context of quasi-hyperbolic utility when the first "real" self is making consumption decisions, because the long-run self is effectively a self with exponential utility (he might have a $\beta$ term in his utility function, but since he takes no immediate actions his present-orientedness is irrelevant). In our present context, the difference between the two variants is unimportant, since the smoking action occurs in Period 1, after Period 0. 
cause Self 2.

The objection to the precommitment criterion is its arbitrariness. Why privilege Self 0 rather than some later self? Moreover, if followed literally the criterion is ambiguous: one period later, Self 1 will have become "Self 0 " and the social planner would have to undo the earlier decisions to follow the desires of the new current self. Of course, the criterion is not meant to be taken literally: what is special about Self 0 is that he is making a choice about something before it becomes a present decision. The idea is that the present-time orientation of a hyperbolically discounting person is illegitimate and we are willing to override consumer sovereignty. One might as well say that for the social planner, $\beta=1$. That is not an unreasonable argument, but it an uncomfortable one. We do not ordinarily argue that tastes are illegitimate. Moreover, the criterion disregards not only the desire of Self 1 , the self making the choice about smoking, but also the desires of Self 2, the post-action self.

\section{The Kaldor-Hicks Criterion}

As we have seen, a smoking ban can be optimal because of hyperbolic discounting under the precommitment criterion in a multiple selves model but once we have adopted the idea of multiple selves, defending that criterion becomes a challenge. An alternative is to apply our standard welfare criterion, but to within the self. We could apply the Kaldor-Hicks criterion: requiring that a change would benefit all selves if appropriate cash transfers were made, but not requiring the transfers themselves. If we accept this logic for policy consequences between different individuals, it seems all the more acceptable within one individual, since we are no longer trading off utilities interpersonally.

The Intraself Kaldor-Hicks Criterion: A change in the value of the choice variables is an improvement if it could be combined with money transfers such that the combined changes would increase the utility of at least one self and reduce the utility of none.

The intraself Kaldor-Hicks criterion takes the laissez faire outcome as the base and asks whether the winners from a change would be willing to 
compensate the losers. ${ }^{4}$ This captures the idea with which we started that a vice causes more future disutility than it causes present utility.

Like the precommitment criterion, the intraself Kaldor-Hicks criterion does not suggest changing consumption from laissez faire in the present model. Because the discount rate exceeds the interest rate, a later self could not compensate an earlier self for saving more.

The smoking choice of $X=0$ or $X=1$ is different. It adds $(X-\beta \delta \alpha X)$ to Self 1's utility and $-\alpha X$ to Self 2's. Would Self 2 pay enough to change Self 1's laissez faire decision of $X=1$ ? Selves 1 and 2 never meet, so the transaction is not possible, but Kaldor-Hicks only requires a potential Pareto improvement, not an actual one. There is a complication, however: Self 1 cares about Self 2's consumption level, so a dollar payment from Self 2 to Self 1 raises Self 1's utility by less than one dollar. Moreover, Self 0's utility is also affected by any transaction between Self 1 and Self 2 . Thus, when we start to consider transfers, the question of whether a payment would compensate is more complicated than it would be between strangers.

Since Selves 0 and 2 both might benefit from the smoking ban, let us imagine both of them making payments to Self 1 in exchange for the ban, payments to Self 1 of $P_{0}$ and $P_{2}$ as measured in giving- period dollars. Since our starting point is $U\left(C_{t}\right)=W$ in each period, the differences between the utilities when the smoking bargain is made $(X=0)$ and when it is not $(X=1)$ are:

$$
\begin{aligned}
\Delta U_{0}= & \left\{\left[W-P_{0}\right]+\beta \delta\left(W+(1+r) P_{0}+\frac{P_{2}}{1+r}\right)+\beta \delta^{2}\left(W-P_{2}\right)\right\} \\
& \left.-\} W+\beta \delta(W+1)+\beta \delta^{2}(W-\alpha)\right\} \\
= & -P_{0}+\beta \delta\left((1+r) P_{0}+\frac{P_{2}}{1+r}-1\right)+\beta \delta^{2}\left(-P_{2}+\alpha\right) \\
\Delta U_{1}= & \left\{W+(1+r) P_{0}+\frac{P_{2}}{1+r}+\beta \delta\left(W-P_{2}\right)\right\}-\{W+1+\beta \delta(W-\alpha)\} \\
= & (1+r) P_{0}+\frac{P_{2}}{1+r}-1+\beta \delta\left(-P_{2}+\alpha\right)
\end{aligned}
$$

\footnotetext{
${ }^{4}$ This is the version of Kaldor (1939); in the version of Hicks (1939) we ask whether the losers would be unwilling to pay the winners to prevent the change; in Scitovsky (1941) a change must pass both tests. The idea is even older. See Chipman \& Moore (1978) for discussion of its history, including, e.g., a discussion of Pareto's and Pigou's views.
} 
and

$$
\begin{aligned}
\Delta U_{2} & =\left\{W-P_{2}\right\}-\{W-\alpha\} \\
& =-P_{2}+\alpha
\end{aligned}
$$

We can find the necessary and sufficient condition for a Pareto improvement by picking $P_{0}$ and $P_{2}$ to make Selves 1 and 2 indifferent about the bargain and then seeing if Self 0's utility rises under the resulting $P_{0}$. Self 2 is indifferent if $P_{2}=\alpha$, from equation (9). Substituting into Self 1's net benefit equation (8), Self 1's net benefit is zero if Self 0 pays him:

$$
P_{0}=\frac{1+r-\alpha}{(1+r)^{2}}
$$

Substituting the values of $P_{2}=\alpha$ and $P_{0}=\frac{1+r-\alpha}{(1+r)^{2}}$ into Self 0's net benefit equation, (7), tells us that Self 0 will derive higher utility from paying $P_{0}$ to ban smoking than from blocking the transaction if

$$
\alpha>1+r
$$

Thus, if the difference between Self 2's loss from smoking and Self 1's gain exceeds the interest rate, smoking should be banned.

Nothing in this argument has relied on hyperbolic discounting. We could have assumed $\beta=1$ and the conclusion would be the same. Thus we have Result 1.

Result 1: The intraself Kaldor-Hicks criterion can justify paternalistic banning of a vice even if discounting is exponential.

Why is hyperbolic discounting inessential? Unlike the precommitment criterion, the intraself Kaldor-Hicks criterion does not rely on conflicting time preferences to justify helping a future self, but on low interest rates. The argument for Result 1 relies not on the altruism of earlier selves to generate utility, but on the willingness of the future self to sacrifice consumption. To see this set $\beta=0$, so earlier selves care nothing for later selves. The precommitment criterion no longer has anything to say about a smoking ban, since Self 0 cares nothing about either Self 1 or Self 2. The intraself Kaldor-Hicks criterion, however, still bans smoking if $\alpha>1+r$, which is to 
say if Self 2 loses more from Self 1's smoking than can be compensated by the rate of interest.

We can think of there being market failure within the self, a missing market for trade of future money for present abstention. If the social planner created that market, he would create gains from trade, and both buyer and seller would benefit when Self 1 sells a smoking ban to Self 2 .

Contrast the conditions under which a smoking ban raises welfare under our two welfare criteria.

$$
\begin{gathered}
\text { Precommitment }: \alpha \in\left(\frac{1}{\delta}, \frac{1}{\delta \beta}\right) \\
\text { Kaldor }- \text { Hicks }: \alpha>1+r .
\end{gathered}
$$

In both, greater smoking damage $\alpha$ makes a ban more attractive. Under the precommitment criterion, the smoking damage has to be large relative to the time preference discount factor, because under hyperbolic discounting $(\beta<1)$. Self 1 attaches more weight to period 1 actions than Self 0 would like. Under the intraself Kaldor-Hicks criterion, the smoking damage has to be large relative to the interest rate, because it then outweighs the fact that Self 1 gets less consumption out of having a period 1 dollar than Self 2, able to wait a period and earn interest on it, would get from that same dollar.

\section{What if Only the Post-Action Self Pays Compensation?}

We have just seen that if $\alpha>1+r$ then Self 2 would be willing to compensate Self 1, with the aid of Self 0 . What if Self 2 had to compensate Self 1 by himself? If Self 0 chose $P_{0}=0$, then Self 1 's net benefit from agreeing not to smoke would be, from equation (8),

$$
\Delta U_{1}=\frac{P_{2}}{1+r}-1+\beta \delta\left(-P_{2}+\alpha\right)
$$

This solves to a necessary payment of

$$
P_{2}^{*}=(1-\alpha \beta \delta)(1+r)\left(\frac{1}{1-\beta \delta(1+r)}\right) .
$$


The three terms of Self 2's payment in (15) illustrates three effects of a transfer by Self 2 to Self 1 to stop smoking. First, Self 1 must be compensated for the direct effect of not smoking, a loss of 1 to himself that is partly compensated for by the $\alpha \beta \delta$ in utility to himself from Self 2's benefit. Second, if $P_{2}$ is measured in period 2 dollars, we must multiply it by $(1+r)$ to get the value in period 1 dollars. Third, Self 1 suffers disutility from the reduction in Self 2's utility that results from Self 2's making the payment, and Self 2 's payment to him must be inflated by $\frac{1}{1-\beta \delta(1+r)}$ to compensate for that. Note that if Self 1 cares only about the present $(\beta \delta=0)$ then the necessary payment is simple: $P_{2}=1+r$. The complexity arises from Self 1's concern about period 2 consumption.

What condition on the harm from smoking $\alpha$ is necessary for Self 2 to be willing to pay the entire compensation to Self 1 ? Self 2 is willing to pay so long as $P_{2} \geq \alpha$. Setting $P_{2}=\alpha$ in equation (15) and solving for $\alpha$, however, yields

$$
\alpha=1+r
$$

which is the same as the critical value for banning smoking when Self 0 also paid compensation.

Why is it that Self 0's benefit from banning smoking has no effect on when smoking should be banned? One would think that if $\alpha$ is slightly too small for Self 2 to be willing to pay enough to Self 1 to stop smoking then Self 0's additional contribution would tip the balance. Remember, though, that Self 0 only benefits from a smoking ban if $\alpha>\frac{1}{\beta \delta}$. Thus, the interval of $\alpha$ for which banning smoking would be optimal but Self 2 is unwilling to pay the entire compensation is $\left[\frac{1}{\beta \delta}, 1+r\right]$. This, however, is an empty interval, because by the consume-early assumption, $\frac{1}{\beta \delta}>1+r$. Whenever Self 2 is unwilling to pay enough to Self 1 for him to stop smoking, Self 0 is unwilling to pay him anything at all, so Self 0's willingness to pay ends up being irrelevant. That irrelevance is why the hyperbolicity parameter $\beta$ fails to show up in the optimality condition for regulation.

On the other hand, shouldn't Self 0's benefit from smoking affects the optimality condition for smoking? Couldn't it happen that a bargain helps Selves 1 and 2, but to the detriment of Self 0, who does want Self 1 to smoke if $\alpha<\frac{1}{\delta}$ ? This cannot happen, because Self 0 also benefits from Self 2's payment to Self 1 . If Self 2's payment of $P_{2}$ to Self 1 makes Self 1 indifferent 
about whether to smoke or not, then Self 0 is no worse off either, since he gains as much from Self 1's added consumption as from Self 1's reduced smoking, plus Self 0 gets more benefit from Self 2's reduced smoking damage than loss from Self 2's reduced consumption.

Self 0's willingness to pay to stop Self 1 smoking does become relevant in one circumstance, however: if incomes are low relative to the utility from smoking. I have skirted one requirement for the Kaldor-Hicks payment that drives Result 1: Self 2 must be able to afford to pay it. If $P_{2}^{*}>W$, then Self 2 is too poor to pay enough to Self 1 to induce him to stop smoking. Selves 1 and 2 together, however, might still have enough income and willingness to do so. Self 0's

What is efficient under the intraself Kaldor-Hicks criterion does depend on the distribution of wealth- that initial allocation of decision rights described above. In the transaction just described, Self 2 pays $\frac{(1+r)(1-\alpha \beta \delta)}{1-\beta \delta(1+r)}$ to Self 1 . If it is Self 2 alone who pays Self 1, this requires that Self 2's income be large enough: $W \geq \frac{(1+r)(1-\alpha \beta \delta)}{1-\beta \delta(1+r)}$. Otherwise, Self 2 could not pay Self 1 enough to compensate for Self 1's loss of utility from smoking. If it is both Selves 0 and 2 who pay Self 1, then if Self 2 reaches his budget constraint Self 0 must be able to pay the remainder. The amount Self 0 is willing to pay when Self 2 pays $W$ can be found by substituting $P_{2}=W$ in Self 0's net benefit equation, (7) and solving for $P_{0}$, which yields:

$$
P_{0}=\frac{\beta \delta\left(\frac{W}{1+r}-1+\delta \alpha-\delta W\right)}{1-\beta \delta(1+r)} .
$$

The main point of equation (16) is that Self 0 is willing to pay something to make the nonsmoking agreement go through if Self 2's income is insufficient. The very complexity of the equation, however, and the fact that it remains positive even if $\beta=1$ and there is no hyperbolic discounting, illustrates a second point: Self 0's gain from Self 2's payment to Self 1 is not entirely due to its effect on smoking. There is a second benefit to Self 0: that consumption is transferred from Self 2 to Self 1 . Given the consume-early assumption of heavy discounting, Self 0 prefers consumption to be moved up in time. We have constrained the moving up of consumption by assuming that borrowing is impossible, but the Kaldor-Hicks payments have the same effect. This will become clearer in the next section when we do allow borrowing. 


\section{Borrowing and Saving in the Linear-Utility Model}

\section{Should the Social Planner Permit Borrowing?}

I have assumed borrowing was impossible. What if the social planner could replicate borrowing across selves by a system of age-dependent taxes and transfers? Under laissez faire, each self consumed his entire endowment rather than save. Would they now borrow?

The precommitment criterion says that the social planner should permit borrowing, which would transfer all consumption to period 0 . Self 0 would choose to consume all three selves' endowments because of the assumption that the rate of time preference is high and the utility function is linear in consumption.

The intraself Pareto and Kaldor-Hicks criteria lead to a different result: they would not instruct the government to replicate borrowing. Permitting borrowing would help Self 0, but hurt Selves 1 and 2. By assigning all wealth to Self 0 , it would prevent any exchange of goods for money on which to base a potential Pareto improvement.

The multiple selves paradigm is a bigger change from standard normative economics than it might first seem. The paradigm provides a plausible reason for banning smoking, but it weakens the argument against usury laws. The argument for banning smoking is that the ban hurts the present self less than it helps the future self. If the two could bargain across time, they would do so and both would be better off. The conventional argument against usury laws is that if someone accepts a loan, he must think that the benefit in current consumption is worth the loss in future consumption. That is just to say that Self 0 benefits from borrowing, however, despite the loss to Selves 1 and 2. A usury law banning borrowing would hurt Self 0 but benefit Selves 1 and 2, so under the intraself Kaldor-Hicks criterion, we cannot say that the change is either a gain or a loss. We would have to resort to some other argument to justify the allocation of property rights among the three selves. ${ }^{5}$

\footnotetext{
${ }^{5}$ Richard Posner (1985, p. 93) says "If you asked a random group of economists how to assign property rights in a new society with a literate population so as to maximize the prices (time quantities), explicit and implicit ("shadow"), asking and offer, in the society they would almost certainly begin by giving each mentally competent adult the property rights to his own labor." In the intraself context, that would imply a ban on borrowing,
} 


\section{The Effect of Borrowing on the Optimality of Smoking}

I just discussed the implications of borrowing for consumption, but borrowing has implications for the optimality of smoking too. If borrowing is possible, that affects whether a Kaldor-Hicks improvement can be made. The possibility of borrowing has an income effect. It alters the wealth controlled by each self and thus affects their willingnesses to pay for smoking changes.

Let us start from a position in which borrowing is possible without intervention by the social planner: Selves 0 and 1 may borrow against future income for present consumption. We will assume they borrow at the same rate $r$ at which they can lend.

The laissez faire result is that Self 0 would borrow and consume the entire endowment. Selves 1 and 2 would consume zero, and Self 1 would smoke. The extreme consumption result occurs because of the assumptions of linear utility and the rate of time preference being higher than the interest rate.

Under the precommitment criterion, the laissez faire outcome of zero consumption for Selves 1 and 2 is optimal, but not the outcome of Self 1 smoking (except in the extreme case of $\beta=0$, at which Self 0 is indifferent about Self 1 smoking). If $\beta$ is positive Self 0 would still borrow and consume all of the endowments, but would use the same critical value of $\alpha>1 / \delta$ as before to ban smoking.

The intraself Pareto improvement and Kaldor-Hicks criteria, agree with the precommitment criterion in not requiring any change from zero consumption by Selves 1 and 2. Any such change would harm Self 0, and the harm to Self 0 would be exactly balanced by benefit to the other two selves, a matter of redistribution rather than any improvement in social surplus.

What is more surprising is that unlike when borrowing was impossible, the Kaldor-Hicks criterion now does not require a ban on smoking whenever the present value of utility harm exceeds the utility benefit $(\alpha>1+r)$.

There is no scope for mutually beneficial trade of wealth for wealth, of course, but the possibility of borrowing has also eliminated the possibility of

so that each self would be able to keep (or pass along) the fruits of his own period's labor. 
mutually beneficial trade of wealth for a smoking ban. As a result of Self 0's borrowing, Selves 1 and 2 have zero wealth. Self 2 cannot offer any wealth to Self 1 in exchange for the smoking ban.

Self 0 could offer some wealth to Self 1 in exchange for a smoking ban. Would he offer enough?

The effect on Self 0's utility of a bargain in which he gives $P$ to Self 1 in exchange for a smoking ban is

$$
-P+\beta \delta(-1+P)+\beta \delta^{2} \alpha
$$

The minimum $P$ that Self 1 would accept is $P=\frac{1-\beta \delta \alpha}{1+r}$. Substituting that $P$ into the expression for Self 0's utility change and solving for $\alpha$ yields the condition for Self 0's utility to rise from the bargain:

$$
\alpha>\frac{1+\delta \beta r}{\beta \delta(1-\beta \delta+\delta(1+r))}
$$

Condition (18) is stronger than the precommitment criterion's condition of the smoking damage being $\alpha>1 / \delta$, but weaker than Self 1's condition for not smoking, $\alpha>\frac{1}{\beta \delta}$. If $\beta=1$, it is equivalent to $\alpha>\frac{1}{\delta}$, and regulation is unnecessary because Self 1 will abstain from smoking whenever Self 0 would be willing to pay him not to smoke. ${ }^{6}$ If, however, discounting is quasihyperbolic so $\beta<1$, a smoking ban raises welfare under the Kaldor-Hicks criterion whenever the smoking damage is greater than $1 / \delta$ but less than the $\alpha$ in inequality (18).

Result 2: If the person borrows enough against his future income, the KaldorHicks criterion can support a smoking ban only if discounting is hyperbolic.

Allowing borrowing has changed the distribution of wealth. Before, Selves 0, 1, and 2 each controlled $W$ under laissez faire (as well as Self 1 controlling the value of $X$, a property right which is part of his economic wealth). Now, Self 0 controls all three incomes by being able to borrow. Self

${ }^{6}$ The right-hand- side is less than $1 / \beta \delta$ because $(1+\delta \beta r) \beta \delta<\beta \delta(1-\beta \delta+\delta(1+r))$ because $\beta \delta<\beta \delta(1-\beta \delta+\delta$ and $(\delta \beta r) \beta \delta<\delta \beta r$. The right-hand-side is at least as great as $1 / \delta$ because $(1+\delta \beta r) \geq \beta(1-\beta \delta+\delta(1+r))$ because $1 \geq \beta(1-\beta \delta+\delta)$ because that reaches a maximum at $\beta=1$, when $\beta(1-\beta \delta+\delta)=1$. 
1 only controls the value of $X$ and what income Self 0 lets him control. Self 2 only controls what income Self 1 lets him control. Thus, Self 2 is too poor to participate in any Coasean bargain, though Self 0 can still do so. Since Self 0 can still participate, however, if discounting is quasi-hyperbolic then Self 0 is willing to pay enough to Self 1 to make him agree not to smoke. The only problem is enforcing such a bargain, and that is where government regulation can be helpful.

This is the driving force behind the smoking license idea of Bhattacharya \& Ladkdawalla (2004). In a model with time inconsistency induced by quasihyperbolic discounting, they suggest the use of voluntary smoking licenses that a person could purchase to constrain his future smoking. These licenses would subject the future self to high cigarette taxes, but would also entitle the future self to a lump-sum transfer that would make him better off overall. Thus, all selves can be made better off, a Pareto improvement. In the context of the present paper's model, such a scheme would allow Self 0 to buy a ban on his future Self 1's smoking. Self 1 would receive the purchase price, which would be set high enough to increase his utility. Of course, under the KaldorHicks criterion Self 0's willingness to pay that much would be sufficient for a ban to be welfare-improving.

Finally, it is worth noting that although the Kaldor-Hicks criterion does not require a smoking ban when discounting is exponential, borrowing is unlimited, and smoking damage is large, it does not argue against one either. Suppose we think of a smoking ban as the allocation of the property right of the smoking decision to Self 2 instead of Self 1 . The re-allocation is purely hypothetical since Self 2 does not exist at the time of the decision, but it illustrates how the initial allocation affects the optimal outcome. Smoking would not occur under laissez faire because it would not maximize Self 2's utility. The intraself Kaldor-Hicks criterion would be satisfied, because Self 1 would have no money with which to buy $X=1$ from Self 2 . In fact, if $\alpha<1+r$ Self 1 would not wish to buy it even if he did have the funds, because the value of smoking to him is less than its cost to Self 2. Similarly, if Self 0 started by controlling the decision (as he would, in effect, under the precommitment criterion), Self 1 would be unable to buy the right to smoke from Self 0, and Kaldor-Hicks would accept a smoking ban as optimalthough in that case, if Self 1 had the funds, he would be willing to buy the right from Self 0 and Self 0 would be willing to sell. The Kaldor-Hicks 
criterion's recommendations depends on the initial allocation of property rights.

\section{What if the Interest Rate is High and Income Is Saved?}

Suppose we drop the consume-early assumption and replace it with a "consume-late" assumption:

$$
\delta \beta>\frac{1}{1+r}
$$

In equilibrium Selves 0 and 1 would save their entire income under laissez faire, a result that neither the precommitment criterion nor Kaldor-Hicks would change.

Self 1 would, however, still smoke, because the effect of smoking on Self 2 's utility is unaffected by the rate of interest. And the precommitment criterion would still ban smoking.

Foreshadowing Result 3 below, however, Kaldor-Hicks would no longer support a smoking ban except under hyperbolic discounting. In our hypothetical transaction, Selves 1 and 2 transfer consumption to Self 1, but now Self 1 would find this undesirable, a penalty rather than a reward. Under the consume-late assumption, Self 1 gains utility of 1 from his own consumption of 1 unit of income, but utility of $\frac{1+r}{\delta \beta}>1$ from Self 2's consumption. Self 0 would be passing along his entire endowment to Self 1 anyway, and so could not credibly condition the payment on Self 1 not smoking. Hence, potential gains from trade are absent.

\section{A Model with Concave Utility and Money Transfers across Time}

Our method has been to ask whether the losers from smoking would be willing to compensate the winner for stopping. We have seen that (1) internalities can justify a smoking ban when borrowing is constrained, (2) if borrowing is unconstrained, the argument fails because the future self is too poor to pay compensation, and that (3) if the interest rate is so high that all income is saved, the arguments fails because the present self would not want to accept the payment and reduce the future self's consumption. Those crosstime consumption decisions were corner solutions because of the assumption 
of linear utility. What if we introduce a motive for partial, interior-solution "bequests" from one self to a later self?

One might guess from Barro (1974) and Becker (1974) that bequests would have an important effect. Barro (1974) applies the idea of "Ricardian equivalence" to intergenerational debt. If the government taxes a future generation to pay a pension to the present generation, the direct effect is to make the present generation consume more and the future generation less. If the present generation cared enough to leave a bequest to the future generation, however, then when the pension is introduced the bequest will simply be increased to take account of the increase in future taxes. Becker (1974) introduces the "Rotten Kid Theorem" that even an non- altruistic member of a family will act to increase family income if the family's altruistic head gives transfers to every member of the family.

Barro's model is simply about transfers of wealth, on which the KaldorHicks criterion is silent, but he makes the point that bequests can undo the effect of government intervention. Becker (1974, p. 1078) goes further. Besides the Rotten Kid Theorem (that each family member will maximize family income if some altruistic member makes transfers to everyone), the paper includes what we might call the Nightlight Problem. Imagine an altruistic husband who must decide whether to read in bed at night, when he knows that his wife would pay ten dollars if he did not and he would pay no more than six dollars for the right to read. Being altruistic, he cares about his wife's utility enough to be making monetary transfers to her. Given that he is going to reduce his own utility to increase his wife's, he wants to do it as efficiently as possible. He will refrain from reading at night, because if he doesn't mind inflicting ten dollars of harm on his wife, he can do it by giving her ten dollars less to spend. ${ }^{7}$ The Nightlight Problem has the same flavor as our smoking example. Will interior solutions for altruistic transfers eliminate inefficient behavior ${ }^{8}$

\footnotetext{
${ }^{7}$ Becker also looks at the nightlight problem from the point of view of the wife, in a closer analogy to the Rotten Kid Theorem's result that even a selfish child will act to increase family income. If the wife controls the nightlight decision, she will allow the husband to read at night if that is efficient, because he will compensate her for her lower utility with a bigger cash transfer.

8 Bergstrom (1989) has shown that the efficiency conclusion and other extensions of the Rotten Kid Theorem to more than one consumption good require caveats. If the wife chooses the amount of nightlight in Bergstrom's example, she will choose an inefficiently
} 
To see what happens when consumption decisions are interior solutions, let us now make the utility of consumption strictly concave, a function $U(C)$ with $U^{\prime}>0, U^{\prime \prime}<0$, and $C \stackrel{\text { limit }}{\rightarrow} 0 U^{\prime}(C)=\infty$. Let us assume that borrowing is limited to an amount $\bar{B}$ in borrowing period dollars, where we will not assume that this constraint is binding. Let us also abandon the consumerearly assumption: do not assume that the the interest rate $r$ and the discount factors $\beta$ and $\delta$ have any restricted relation to each other.

Let us imagine a Kaldor-Hicks transfer of $P$ from Self 2 to Self 1 to ban smoking, with $P$ measured in period 2 dollars. This payment will cost Self 2 amount $P$ and increase Self 1 's consumption by $P /(1+r)$. In addition, Self 1 may be borrowing amount $B \leq \bar{B}$, which will cost Self 2 amount $(1+r) B$ in consumption.

Let $W_{1}$ equal Self 1's income of $W$ plus whatever Self 0 saves, minus whatever Self 1 borrows from him. Self 1 is constrained to spend no more than his income on present consumption, so

$$
C_{1} \leq W_{1}+\bar{B}+\frac{P(1-X)}{1+r} .
$$

If this is binding, then Self 1 is borrowing the full amount $\bar{B}$ from Self 2 . If it is not binding, then Self 1 is saving or is borrowing less than $\bar{B}$.

Self 2's consumption will be equal to his income of $W$ plus $(1+r)$ times the amount Self 1 saves, $\left(W_{1}-C_{1}\right)$, this last being negative if Self 1 is borrowing instead of saving:

$$
C_{2}=W+(1+r)\left(W_{1}-C_{1}\right)
$$

Self 1's maximization problem is to choose $X, C_{1}$, and $C_{2}$ to maximize

$$
U_{1}\left(C_{1}, C_{2}, X\right)=X+U\left(C_{1}\right)+\beta \delta\left(-\alpha X+U\left(C_{2}\right)\right)
$$

subject to the constraints

$$
\begin{aligned}
& \text { (a) } C_{1} \leq W_{1}+\bar{B}+\frac{(1-X) P}{1+r} \\
& \text { (b) } C_{2}=W+(1+r)\left(W_{1}-C_{1}\right)
\end{aligned}
$$

small amount of light because she knows the husband's choice of monetary transfer will depend on her choice and she acts strategically. In the present paper, Self 2 does not control the amount of smoking, so no such strategic effect will be present. 
Constraint (a) is either binding or not binding. Consider first the case where it is not binding. Instead, Self 1 finds it optimal to save, or to borrow less than $\bar{B}$. Then we can substitute for $C_{2}$ from constraint (b) and write the problem as to maximize by choice of $C_{1}$ and $X$

$$
X+U\left(C_{1}\right)+\beta \delta\left(-\alpha X+U\left(W+(1+r)\left(W_{1}-C_{1}\right)\right) .\right.
$$

The problem needs no budget constraint, because by definition of the case, income does not constrain the choice of $C_{1}$. Rather, the desire to save constrains it.

In this problem, the condition for choosing $X=1$ is that

$$
1-\beta \delta \alpha>0,
$$

and the first order condition with respect to $C_{1}$ is

$$
U^{\prime}\left(C_{1}\right)+\beta \delta(1+r) U^{\prime}\left(W+(1+r)\left(W_{1}-C_{1}\right)=0\right.
$$

The price $P$ appears in neither of these two optimality conditions. Hence, Self 2's offer of $P$ in exchange for the smoking ban makes no difference. Either Self 1 would abstain from smoking anyway, or he would not be persuaded by the offer of money from Self 2. If discounting is exponential, then it is only Self 2 who would be willing to offer money to Self 1 in exchange for not smoking, because Self 0 shares Self 1's incentives, as we saw earlier. Thus, Kaldor-Hicks no longer can support a smoking ban, as Result 3 states.

Result 3: If discounting is exponential and a person's borrowing constraint is non-binding (including if he is saving a positive amount), then the intraself Kaldor-Hicks criterion does not support a smoking ban.

If Self 1 cares enough about Self 2 to pass savings along to him, then the intraself Kaldor-Hicks criterion does not require Self 1 to give up smoking for the sake of Self 2. If Self 1 is selfish enough not to save, the criterion does require him to give up smoking. Thus, as in the Nightlight Problem, there is no Kaldor-Hicks inefficiency, but it is not because the altruist abstains from seemingly inefficient behavior, but because he will not accept compensation for abstaining.

The intuition behind Result 3 is that when Self 1 is saving, the marginal dollar of saving results in period 2 consumption that gives him as much utility 
(discounted though it is) as if he spent that dollar on period 1 consumption. He would be hurt by anything that transferred that consumption back to period 1. Thus, if he consumes the Kaldor-Hicks payment given him by Self 2 , he is actually worse off.

Similarly, if Self 1 is borrowing less than the limit, he has decided that though overall he would like to reduce Self 2's consumption to increase his own, at the margin, once he has borrowed the appropriate amount, his utility is the same from having Self 2 consume a little as from having himself consume more.

\section{A Binding Borrowing Constraint}

Consider now the case in which constraint (a) in maximization problem (22) is binding, so Self 1 borrows the full amount $\bar{B}$. In that case, we can represent period-2 consumption by

$$
C_{2}=W-(1-X) P-(1+r) \bar{B}
$$

which is period 2 income minus the no-smoking payment minus the repayment of Self 1's borrowing. Self 1's problem is to maximize, by choice of $X$,

$$
X+U\left(C_{1}\right)+\beta \delta(-\alpha X+U(W-(1-X) P-(1+r) \bar{B})
$$

Self 1 will choose to smoke $(X=1)$ if

$1+U\left(W_{1}+\bar{B}\right)+\beta \delta\left(-\alpha+U(W-(1+r) \bar{B})>U\left(W_{1}+\bar{B}+\frac{P}{1+r}\right)+\beta \delta U(W-P-(1+r) \bar{B})\right.$.

When utility was linear, the marginal utility of income was 1 and the payment $P$ had to equal $\frac{(1+r)(1-\alpha \beta \delta)}{1-\beta \delta(1+r)}$, in equation $(15)$. Now that the marginal utility of income is not constant, the necessary payment $P$ must reflect the fact that for both Self 1 and Self 2 the marginal utility of income is changing with income. Depending on the shape of the function $U(C)$, there might or might not be a Kaldor-Hicks transfer that would induce Self 1 to stop smoking. The general case is unenlightening, but consider what happens if our person care only about the present, so $\delta=0$. The payment by Self 2 
necessary to induce Self 1 to stop smoking is then, from inequality (30), such that

$$
1+U\left(W_{1}+\bar{B}\right)=U\left(W_{1}+\bar{B}+\frac{P^{*}}{1+r}\right) .
$$

Self 2 will be willing to pay that amount if income is high high enough $\left(P^{*} \leq W-(1+r) \bar{B}\right)$ and

$$
U\left(W-(1+r) \bar{B}-P^{*}\right) \geq-\alpha+U(W-(1+r) \bar{B}) .
$$

If $U^{\prime \prime}$ is close to zero, so utility is almost linear, and if $r$ is low then the gain in Self 1's consumption utility from the transfer of $P^{*}$ will be close to the loss in Self 0's, and if $\alpha$ is large enough, Self 2 would indeed be willing to pay $P^{*}$. If, on the other hand, the utility of cosumption flattens beyond Self 1 's initial consumption level of $W_{1}+\bar{B}$ but increases enough for lower levels of consumption, then Self 1 will be unwilling to deprive Self 2 of consumption via the transfer of $P^{*}$. Thus, there is a possibility of regulation being optimal for borrowing-constrained individuals, but not a necessity.

This may be easier to see in a numerical example. Assume that $W=1$, $K=6, r=0, B=.2$, and that the utility function has marginal utilities of

$$
\begin{aligned}
U^{\prime}(C) & =2 \text { if } C<2 \\
& =1 \text { if } C>2 .
\end{aligned}
$$

This person has some incentive to arrange the consumption path so that consumption equals at least 2 in each period. We will retain the assumption that smoking yields 1 in utility to Self 1 and $\operatorname{costs} \alpha \in\left(1, \frac{1}{\beta \delta}\right)$ in utility to Self 2 .

(1) Suppose $\beta \delta<.5$, in which case high time preference overrides the incentive to smooth consumption. There is no saving, and Self 2 will pay Self 1 not to smoke. The laissez faire outcome will be $C_{0}=7.2, C_{1}=1, X=1$, and $C_{2}=.8$. If Self 0 or 1 deviates by saving more, he will lose utility at a rate of 1 per reduced consumption unit and gain it at only a rate of $2 \beta \delta$ from his successor's increased consumption. Thus, Self 0 will borrow up to the limit of $B=.2$ from Self 1 , and Self 1 will borrow up to the limit from Self 2. Self 1 will smoke because smoking raises his utility by 1 directly and reduces it only by $\beta \delta \alpha$ through its effect on Self 2 . 
The Kaldor-Hicks Criterion can support a smoking ban if $\beta \delta<.5$ even if $\beta=1$ because Self 1 would accept as little as $(.5-\beta \delta \alpha$ to stop smoking (.5 rather than 1 because his marginal utility of consumption is 2 , whereas smoking only increases utility by 1 ) and Self 2 would be willing to pay up to $\alpha / 2$, an amount greater than .5 since $\alpha>1$. We do not need to resort to payments from Self 0 .

We have seen in Result 2 that hyperbolic discounting can provide a reason for regulation under the Kaldor-Hicks criterion even when the individual is borrowing his entire future income. That continues to be true when he is only borrowing part of it, as we will see by altering the discounting in our numerical example.

(2) Suppose instead that . $5<\beta \delta<1$, in which case consumption smoothing outweighs discounting to some extent. The laissez faire outcome will be $C_{0}=5, C_{1}=2, X=1$, and $C_{2}=2$. If Self 0 or 1 deviates by saving more, he will lose utility at a rate of 1 per increased consumption unit and gain it at the lower rate of $\beta \delta$ from his successor's increased consumption. If he deviates by saving less, he will gain utility at a rate of 1 per increased consumption unit and lose it at the higher rate of $2 \beta \delta$ from his successor's reduced consumption.

Under laissez faire, Self 1 will smoke because it adds $(1-\beta \delta \alpha)$ to his utility.

There is no payment by Self 2 that will persuade Self 1 to stop smoking. A payment of $P$ by Self 2 will have a net effect of $(P-2 \beta \delta P)<0$ on Self 1 's utility, so Self 1 would refuse the payment even if it were not contingent on not smoking.

Self 0 , on the other hand, could pay $P$ to Self 1 in addition to the laissez faire bequest of 3 and Self 1 would have no objection. The effect on Self 0's utility would be to add

$$
-P+\beta \delta(-1+P)+\beta \delta^{2}(\alpha)
$$

Self 1 would accept a payment of as little as $P=(1-\beta \delta \alpha)$ to not smoke. Substituting that for $P$ in expression (33) tells us that Self 0's utility would 
rise after making that payment to stop smoking if

$$
\alpha>\frac{1}{\delta \beta(1-\beta \delta+\delta)},
$$

an expression similar to what we found in conjunction with Result 2 that even with borrowing hyperbolic discounting could justify a smoking ban under the Kaldor-Hicks criterion.

We have assumed that $\alpha<\frac{1}{\delta \beta}$, but since $(1-\beta \delta-\delta)>1$, the critical value of $\alpha$ for Self 0 to be willing to pay to stop smoking is feasible. There is a range of values of $\alpha$ - though narrow one- for which Self 1 would not abstain from smoking unilaterally but would after a payment that Self 0 would be willing to pay. This does rely on hyperbolic discounting, since if $\beta=1$ our condition for Self 0 being will to make the payment reduces to $\alpha>1$, the same condition as for Self 1 to unilaterally abstain from smoking when $\beta=1$. Thus we have Result 4.

Result 4: The intraself Kaldor-Hicks criterion can support a smoking ban for someone whose borrowing constraint is binding or who uses hyperbolic discounting.

\section{Concluding Remarks}

This this paper I have asked whether applying a version of the KaldorHicks criterion to a multiple selves model provides a justification for intervention by a benevolent social planner. It does provide a justification, with caveats. A first requirement is that the activity cause more immediate harm than it creates future benefit. If so, this has a ripple effect under dynamic inconsistency because not only does the far future self suffer more than the near future self benefits, but the present self suffers sympathetically with the far future self. A second requirement is that the extent of the harm outweigh the real cost of transferring consumption to earlier in time, which is the interest rate. A third requirement is that if discounting is exponential the the person not be saving between the time he engages in the harmful activity and the time the harm occurs, or not be borrowing the maximum possible. Otherwise, the earlier self would not value transfers to himself from the future self, and there are no potential gains from trade. Even if the person engaged in the harmful behavior is making a bequest, however, if discounting 
is hyperbolic the Kaldor-Hicks criterion can justify restricting his behavior for the sake of selves prior to himself in time who care more than he does for consequences in the far future.

Thus, we may conclude that hyperbolic discounting and the precommitment condition of maximizing the utility function of the pre- action self are not essential for paternalistic arguments for regulating internalities. For someone who is impatient and constrained in his borrowing, the intraself Kaldor-Hicks criterion can justify regulation even if the person's discounting is exponential. Regulators often are most concerned to regulate the young and poor because they may have poorer information and self-control. The present model suggests a quite different reason: that they are credit constrained and would be willing to accept payment from their future selves to abstain from vice.

Even if the person is saving, the intraself Kaldor-Hicks criterion can justify regulation if discounting is hyperbolic, but for a narrower range of parameters and for a different reason. The two reasons for regulation have different motives. When discounting is exponential, regulation is balancing the vice's harm to the future self against his willingness to give up consumption. If discounting is hyperbolic, regulation is adjusting for the pre-vice self's lack of present-orientedness in balancing the interests of the future selves. Even under hyperbolic discounting, however, the intraself Kaldor-Hicks criterion justifies regulation more narrowly than the precommitment criterion does, because Kaldor-Hicks requires potential compensation to the regulated self. 


\section{References}

Angeletos, George-Marios, David Laibson, Andrea Repetto, Jeremy Tobacman \& Stephen Weinberg (2001) "The Hyperbolic Consumption Model: Calibration, Simulation, and Empirical Evaluation," Journal of Economic Perspectives, 15(3): 47-68 (Summer 2001).

Baltagi, Badi H. \& Dan Levin (1986) "Estimating Dynamic Demand for Cigarettes Using Panel Data: The Effects of Bootlegging, Taxation and Advertising Reconsidered," Review of Economics and Statistics, 68(1): 148155 (February 1986).

Barro, Robert J. (1974) "Are Government Bonds Net Wealth?" Journal of Political Economy, 82(6): 1095-1117 (November/December 1974).

Becker, Gary (1974), "A Theory of Social Interactions," Journal of Political Economy, 82: 1063-1093 (November/December 1974).

Bergstrom, Theodore C. (1989) "A Fresh Look at the Rotten Kid Theoremand Other Household Mysteries," Journal of Political Economy, 97(5): 11381159 (October 1989).

Bernheim, B. Douglas \& Antonio Rangel (2005) "Behavioral Public Economics: Welfare and Policy Analysis with Non-Standard Decision- Makers," SIEPR Discussion Paper No. 04-33, http://ideas.repec.org/p/nbr/ nberwo/11518.html, (June 2005).

Bernheim, B. Douglas \& Antonio Rangel (2007) "Beyond Revealed Preference: Choice Theoretic Foundations for Behavioral Welfare Economics," http://papers.nber.org/papers/w13737 (December 2007).

Bhattacharya, Jay \& Darius Ladkdawalla (2004) "Time-Inconsistency and Welfare," NBER Working Paper No. W10345, http://papers.ssrn. com/sol3/papers. cfm?abstract_id=515239 (March 2004).

Broome, John (1994) "Discounting the Future," Philosophy and Public Affairs, 23(2): 128-156 (Spring 1994).

Coase, Ronald (1960) "The Problem of Social Cost," Journal of Law and Economics, 3: 1-69 (October 1960). 
Chipman, John S. \& James C. Moore (1978) "The New Welfare Economics 1939-1974," International Economic Review, 19 (3): 547-584 (October 1978).

Chung, Shin-Ho \& Richard J. Herrnstein (1961) "Relative and Absolute Strengths of Response as a Function of Frequency of Reinforcement," Journal of the Experimental Analysis of Animal Behavior, 4: 267-272.

Cowen, Tyler (1991) "Self-Constraint versus Self-Liberation," Ethics, 101(2): 360-373 (January 1991).

Frederick, Shane (1999) "Discounting, Time Preference, and Identity," Ph.D. dissertation, http://web.mit.edu/people/shanefre/Thesis_S.Frederick. pdf (August 1999).

Friedman, David D. (1988) "Does Altruism Produce Efficient Outcomes? Marshall versus Kaldor," The Journal of Legal Studies, 17(1): 1-13 (January 1988).

Fudenberg, Drew \& David Levine (2006) "A Dual Self Model of Impulse Control," American Economic Review, 96(5): 1449-1476 (December 2006).

Gruber, Jonathan \& Botond Koszegi (2001) "Is Addiction "Rational"? Theory and Evidence," Quarterly Journal of Economics, 116(4): 1261-1303 (November 2001).

Harris, Christopher \& David Laibson (2001) "Dynamic Choices of Hyperbolic Consumers," Econometrica, 69(4): 935-957 (July 2001).

Hicks, J. R. (1939) "Foundations of Welfare Economics," Economic Journal, 49(196): 696-712 (December 1939).

Hume, David (1751) An Enquiry Concerning the Principles of Morals.

Kaldor, Nicholas (1939) "Welfare Propositions of Economics and Interpersonal Comparisons of Utility," The Economic Journal, 49(195): 549-552 (September 1939).

Khwajaa, Ahmed, Dan Silverman \& Frank Sloan (2007) "Time Preference, Time Discounting, and Smoking Decisions," Journal of Health Economics, 26 (5): 927-949 (1 September 2007). 
Krusell, Per \& Anthony A. Smith Jr. (2003) "Consumption-Savings Decisions with Quasi-Geometric Discounting," Econometrica, 71(1): 365-375 (January 2003).

Laibson, David (1997) "Golden Eggs and Hyperbolic Discounting," Quarterly Journal of Economics, 112(2): 443-477 (May 1997).

Loewenstein, George (1992) "The Fall and Rise of Psychological Explanations in the Economics of Intertemporal Choice," pp. 3-34 of George Loewenstein and Jan Elster, eds., Choice over Time, New York:Russell Sage Foundation (1992).

Marshall, Alfred (1920) Principles of Economics, The Library of Economics and Liberty, The Liberty Fund, http://www .econlib.org/library/ Marshall/marP14.html\#Bk. III, Ch.VI .

O'Donoghue, Ted \& Matthew Rabin (1999) "Doing It Now or Later," American Economic Review, 89(1): 103-124 (March 1999).

O'Donoghue, Ted \& Matthew Rabin (2003) "Studying Optimal Paternalism, Illustrated by a Model of Sin Taxes," American Economic Review, Papers and Proceedings, 93(2): 186-191 (May 2003).

Parfit, Derek (1982) "Personal Identity and Rationality," Synthese, 53: 227-241.

Parfit, Derek (1984) Reasons and Persons, Oxford University Press, 1984. http://www. oxfordscholarship.com/oso/public/content/philosophy/ 9780198249085/toc.html.

Phelps, Edward S. \& R. A. Pollak (1968) "On Second-Best National Saving and Game-Equilibrium Growth," Review of Economic Studies, 35: 185-199.

Plato "The Symposium of Plato," tr. by E. Piscitelli, http://mysite. verizon.net/thelogos/symtxt.htm.

Posner, Richard A. (1979) "Utilitarianism, Economics, and Legal Theory," The Journal of Legal Studies, 8(1): 103-140 (January 1979).

Posner, Richard A. (1985) "Wealth Maximization Revisited," Notre 
Dame Journal of Law, Ethics 83 Public Policy, 2: 85-106.

Ramsey, Frank P. (1928) "Mathematical Theory of Saving," Economic Journal, 38(152): 543-559 (December 1928).

Rasmusen, Eric (2008) "Some Common Confusions about Hyperbolic Discounting," working paper, http://www .rasmusen.org/special/hyperbolic-rasmusen . pdf (25 January 2008).

Scitovsky, Tibor (1941) "A Note on Welfare Propositions in Economics," Review of Economic Studies, 9(3): 77-88 (June 1941).

Strotz, R. H. (1955) "Myopia and Inconsistency in Dynamic Utility Maximization," Review of Economic Studies, 23(3): 165-180 ( 1955-56).

Whitman. Glen (2006) "Against the New Paternalism: Internalities and the Economics of Self-Control," Policy Analysis no. 563, Cato Instititute, http://www.cato.org/pub_display.php?pub_id=5531\&print=Y (February 22, 2006).

Zerbe, R. O. Jr. (2001) Efficiency in Law and Economics, Aldershot: Edward Elgar (2001). 